\title{
Foraging distribution of breeding northern fulmars is predicted by commercial fisheries
}

\author{
J. H. Darby ${ }^{1,2, *}$, S. de Grissac ${ }^{3}$, G. E. Arneill ${ }^{1,2,4}$, E. Pirotta ${ }^{1,5}$, J. J. Waggitt ${ }^{6}$, \\ L. Börger ${ }^{3}$, E. Shepard ${ }^{3}$, D. Cabot ${ }^{1}$, E. Owen ${ }^{7}$, M. Bolton ${ }^{8}$, E. W. J. Edwards ${ }^{9,10}$, \\ P. M. Thompson ${ }^{9}$, J. L. Quinn ${ }^{1, \#}$, M. Jessopp ${ }^{1,2, \#}$ \begin{abstract}
${ }^{3}$ Biosciences Department, Swansea University, Swansea SA2 8PP, UK ${ }^{4}$ Green Rebel Group, Crosshaven Boatyard, Crosshaven P43 EV21, Ireland ${ }^{5}$ Department of Mathematics and Statistics, Washington State University, Vancouver, WA 98686, USA ${ }^{6}$ School of Ocean Sciences, Bangor University, Isle of Anglesey LL59 5AB, UK ${ }^{7}$ RSPB Centre for Conservation Science, Etive House, Inverness IV2 3BW, UK ${ }^{8}$ RSPB Centre for Conservation Science, The Lodge, Sandy SG19 2DL, UK

${ }^{9}$ Lighthouse Field Station, School of Biological Sciences, University of Aberdeen, Cromarty IV11 8YL, UK ${ }^{10}$ Marine Scotland Science, 375 Victoria Rd, Aberdeen AB11 9DB, UK
\end{abstract} \\ ${ }^{1}$ School of Biological, Environmental and Earth Sciences, University College Cork, Cork T23 N73K, Ireland \\ ${ }^{2}$ MaREI Centre for Energy, Climate and Marine, Environmental Research Institute, University College Cork, Cork P43 C573, Ireland
}

\begin{abstract}
Habitat-use and distribution models are essential tools of conservation biology. For wide-ranging species, such models may be challenged by the expanse, remoteness and variability of their habitat, these challenges often being compounded by the species' mobility. In marine environments, direct observations and sampling are usually impractical over broad regions, and instead remotely sensed proxies of prey availability are often used to link species abundance or foraging behaviour to areas that are expected to provide food consistently. One source of food consumed by many marine top predators is fisheries waste, but habitat-use models rarely account for this interaction. We assessed the utility of commercial fishing effort as a covariate in foraging habitat models for northern fulmars Fulmarus glacialis, a species known to exploit fisheries waste, during their summer breeding season. First, we investigated the prevalence of fulmar-vessel interactions using concurrently tracked fulmars and fishing vessels. We infer that over half of our study individuals associate with fishing vessels while foraging, mostly with trawl-type vessels. We then used hidden Markov models to explain the spatio-temporal distribution of putative foraging behaviour as a function of a range of covariates. Persistent commercial fishing effort was a significant predictor of foraging behaviour, and was more important than commonly used environmental covariates retained in the model. This study demonstrates the effect of commercial fisheries on the foraging distribution and behaviour of a marine top predator, and supports the idea that, in some systems, incorporating human activities into distribution studies can improve model fit substantially.
\end{abstract}

KEY WORDS: Fisheries - Discards - Marine conservation - Foraging behaviour - Habitat use · Anthropogenic food source

\section{INTRODUCTION}

Understanding the drivers of species' distributions is a key objective in conservation biology. Statistical modelling allows us to identify these drivers (Elith \&

*Corresponding author: jamie.darby@ucc.ie

\#These authors contributed equally to this work
Leathwick 2009) and to subsequently predict distribution patterns (e.g. Scales et al. 2016). Ideally, habitat use models incorporate environmental covariates that are known to reflect food availability - for example, vegetation type in terrestrial systems (Vynne

(C) The authors 2021. Open Access under Creative Commons by Attribution Licence. Use, distribution and reproduction are unrestricted. Authors and original publication must be credited. 
et al. 2011) and primary productivity in marine environments (Nur et al. 2011). In terrestrial systems, these descriptors work well because the associated producers are commonly fixed in space and time (e.g. Fryxell et al. 2004, Smit 2011). In marine environments, equivalent descriptors are more elusive because prey patches are transient and less predictable (Fauchald 2009). For example, chlorophyll a (chl a) concentration and sea surface temperature (SST) are often used as a proxy for productivity and prey abundance (e.g. Tremblay et al. 2009, Domalik et al. 2018, Serratosa et al. 2020) but with low predictive power for higher predator behaviour or distribution (e.g. Kane et al. 2020). This is possibly due to spatio-temporal lags between environmental conditions that promote productivity and prey aggregations targeted by marine top predators (e.g. Whitehead et al. 2010, McGowan et al. 2013, Torres et al. 2015). It may also be that these variables predict prey biomass rather than availability (Boyd et al. 2015, Waggitt et al. 2018). As a result, static variables such as water depth, distance to colony and seabed slope are often found to better represent marine predator distribution (Amorim et al. 2009, Critchley et al. 2020). Such habitat descriptors may function in combination to enhance prey availability (e.g. Stevick et al. 2008, Scott et al. 2013). Although many studies have examined the predictive power of these oceanographic features in explaining marine distributions (Tremblay et al. 2009), the extent to which these effects are moderated by human activities has seldom been investigated.

Human activities have the potential to repel or attract species, for example through persistent habitat disturbance (Sauvajot et al. 1998) or provisioning of an extra food source (Newsome et al. 2015). In a marine setting, food sources derived from human activity usually originate from the fishing industry, either through depredation (e.g. Cosgrove et al. 2013) or through scavenging of offal and discards (Bicknell et al. 2013, Giménez et al. 2021). This association with human activity and waste can lead to negative effects, including plastic ingestion by urban scavengers (Caldwell et al. 2020), higher likelihood of human-wildlife conflicts (Cronin et al. 2016, Newsome \& Van Eeden 2017) and the intake of food of lower nutritional value than natural prey (Grémillet et al. 2008).

Seabirds are widely distributed marine predators, but are experiencing global declines (Paleczny et al. 2015). Habitat-use and distribution models are essential tools in seabird conservation, as they can be used to identify areas of concern where seabirds and human activities co-occur (Critchley et al. 2018, Waggitt et al. 2020), and to prioritise areas for protection (Lascelles et al. 2012, McGowan et al. 2013). Many previous studies have focussed on the potentially harmful overlap between fisheries and seabirds in terms of bycatch risk (e.g. Tuck et al. 2011, Torres et al. 2013, Clay et al. 2019). However, at least 29 seabird species use fishing vessels as a source of food, through scavenging of discards or offal (Bicknell et al. 2013), or depredation of bait from baited gears (Dunn \& Steel 2001), with studies showing how seabirds actively associate with vessels to forage on these products of fisheries (e.g. Bodey et al. 2014, Pirotta et al. 2018). Therefore, the distribution of commercial fishing effort might be a suitable predictor of foraging distribution for these marine predators. This could be through individuals co-occurring in the same productive areas as fishing vessels, but is more likely through vessel-attending species targeting areas of known vessel intensity in order to exploit fisheries waste (Collet \& Weimerskirch 2020) or depredate catches.

The northern fulmar Fulmarus glacialis, hereafter 'fulmar', is a far-ranging, pelagic-foraging seabird that both benefits and suffers from fisheries interactions. It is one of the most commonly bycaught seabird species in the North Atlantic (Fangel et al. 2015, Hedd et al. 2016) and Alaskan fisheries (Dietrich et al. 2009). Fulmars are also vulnerable to other human activities and by-products, such as oil extraction (Fox et al. 2016) and plastic pollution (Acampora et al. 2017). Fulmars have undergone dramatic range expansion over the last 2 centuries, spreading from Iceland and St. Kilda through the UK, Ireland and on to the north coast of Europe (Burg et al. 2003). The drivers underlying this expansion likely include both the exploitation of fisheries waste (Fisher 1952, Phillips et al. 1999) and changing patterns of human exploitation (Gordon 1936, Thompson 2006). Currently, however, fulmars are in decline throughout much of their recently established range, observed both in colonies (Cordes et al. 2015, JNCC 2020) and at sea (Sherley et al. 2020). There is therefore an urgent need to better understand the drivers of their distribution when foraging at sea, and to investigate the causes of their recent declines.

We hypothesised that the foraging distribution of adult breeding fulmars could be better predicted using commercial fishing effort alongside a range of static and dynamic environmental variables. Using tracking data from fulmars and fishing vessels in Ireland and the UK, we estimated the prevalence of fulmar-fisheries interactions during the summer 
breeding season by looking at direct associations between the vessel and fulmar tracks. We then examined how fulmar foraging distribution was associated with commercial fishing effort over a broad spatio-temporal scale, comparing its importance as a habitat descriptor to other environmental variables. Finally, we incorporated fishing data and other significant environmental descriptors into models of fulmar foraging distribution over the range covered by our empirical data. The aim of this study was to infer that fulmar foraging distribution is influenced by commercial fishing effort, and that distribution models can be improved by acknowledging links between marine predators and human activity.

\section{MATERIALS AND METHODS}

\subsection{Data collection}

A total of 102 breeding adult fulmars were successfully tracked from Little Saltee, Ireland, the Isles of Scilly, England, and several Scottish mainland and island colonies between 2009 and 2019 (Table 1, Fig. 1). Fulmars were caught by hand, hand net or noose-pole from the nest. PathTrack Nanofix wireless enabled $(10 \mathrm{~g})$, Pathtrack Nanofix archival (15 g) or MobileAction iGotU gt-120 tags $(\sim 17 \mathrm{~g})$ were attached to feathers on the centre of the bird's back, directly above the centre of gravity, using Tesa ${ }^{\circledR} 4651$ waterproof tape. All tag types record the same high accuracy $(\sim 3 \mathrm{~m})$ GPS fixes. To mitigate potential negative impacts of tag attachment, total weight of the tag and attaching material were less than $3 \%$ of the total mass of the bird $(2.19 \pm 0.39 \% \mathrm{SD}$, max. $3.2 \%)$. Despite these considerations, we acknowledge that negative effects remain difficult to detect, control and quantify and could still lead to behavioural anomalies (Vandenabeele et al. 2014, Cleasby et al. 2021).

Tags were programmed to record locations at regular intervals. Depending on tag type and the intended duration of the deployment, this interval ranged from 1.5 to $10 \mathrm{~min}$ in the majority of birds,
Table 1. Deployment sites and number of northern fulmar individuals and trips at each site. Stages are early chick rearing (ECR) and incubating (INC)

\begin{tabular}{lcccc} 
Colony & Year(s) & Birds & Trips & Stage \\
\hline Annet, Isles of Scilly, England & 2010 & 1 & 1 & ECR \\
Bullers of Buchan, Aberdeenshire, & 2012 & 4 & 10 & ECR \\
$\quad$ Scotland & & & & \\
Copinsay, Orkney, Scotland & $2010-2013$ & 9 & 20 & ECR \\
Eynhallow, Orkney, Scotland & $2009-2011,2017$ & 23 & 42 & INC \& ECR \\
Fair Isle, Shetland, Scotland & $2011-2014$ & 9 & 11 & ECR \\
Little Saltee, Co. Wexford, Ireland & $2018-2019$ & 10 & 29 & INC \\
Muckle-Skerry, Orkney, Scotland & 2014 & 8 & 18 & ECR \\
Hirta, St. Kilda, Scotland & $2011-2012$ & 35 & 48 & ECR \\
St. Martin, Isles of Scilly, England & 2011 & 1 & 1 & ECR \\
Swona, Orkney, Scotland & 2012 & 1 & 1 & ECR \\
Whinnyfold, Aberdeenshire, & 2012 & 1 & 2 & ECR \\
$\quad$ Scotland & & & &
\end{tabular}
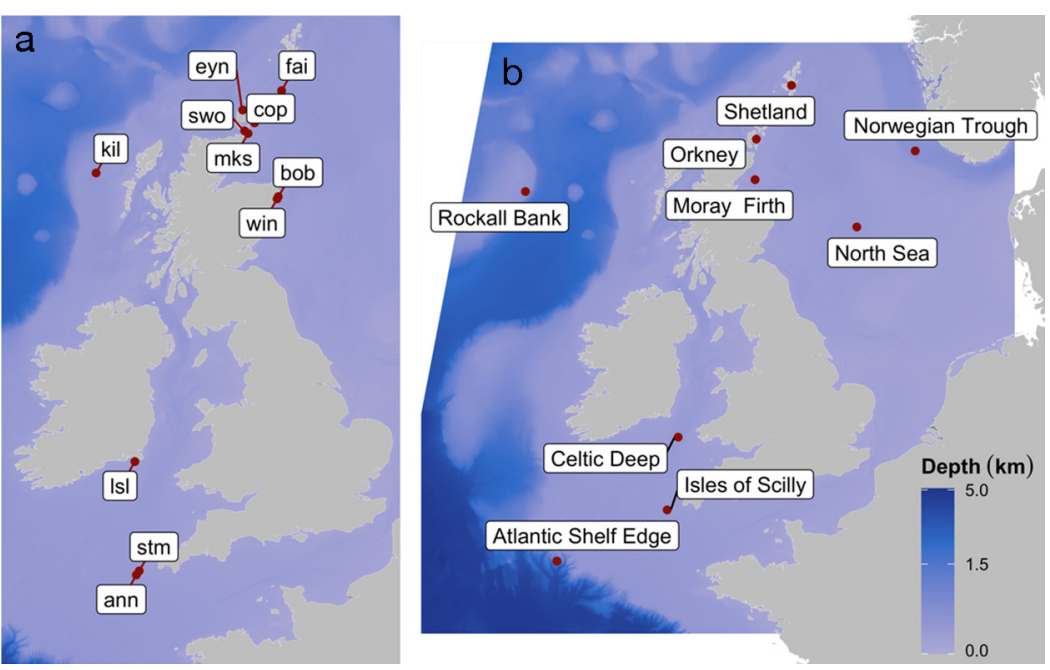

Fig. 1. (a) Locations of northern fulmar colonies and (b) major geographic features referenced in the text. Colonies are Annet (ann), Bullers of Buchan (bob), Copinsay (cop), Eynhallow (eyn), Fair Isle (fai), Hirta, St. Kilda (kil), Little Saltee (lsl), Muckle-Skerry (mks), St. Martin (stm), Swona (swo) and Whinnyfold (win)

as well as a small subset of birds on Hirta, St. Kilda, with tags set to record every 15 or 20 min. Nests of tagged individuals were monitored, and data from tags were either remotely downloaded (PathTrack Nanofix wireless enabled) or retrieved after several days when the tagged bird had undertaken at least 1 foraging trip. All work was conducted under licences from the British Trust for Ornithology and the Irish National Parks and Wildlife Service. All data analyses were undertaken using $\mathrm{R}$ version 3.6.3 (R Core Team 2020). Foraging trips were originally defined as periods of $>1 \mathrm{~h}$ that the bird spent $>3 \mathrm{~km}$ from the colony. Distance from the colony and total distance travelled were calculated using the 'raster' package (https://cran.r-project.org/web/ 
packages/raster/; Tables S1 \& S2 in the Supplement at www.int-res.com/articles/suppl/m679p181_ supp.pdf). Data were further filtered to include foraging trips that contained $>100$ GPS fixes where birds travelled $>10 \mathrm{~km}$ from the colony to exclude small trips that may have occurred because of disturbances at the colony. Points within $5 \mathrm{~km}$ of the colony were also removed as they likely encompassed colony-related behaviours (Bodey et al. 2014).

\subsection{Fulmar-vessel foraging interactions}

First, we aimed to establish the extent to which adult fulmars tracked in this study foraged in association with fishing vessels during the breeding season. Fishing vessel tracking data were sourced from the Vessel Monitoring System (VMS). Irish VMS data were sourced from the Irish Marine Institute, while UK VMS data were sourced from Marine Scotland Science. VMS provides GPS locations of fishing vessels $>12 \mathrm{~m}$ long, approximately every $2 \mathrm{~h}$. UK VMS data consisted of almost exclusively UK-flagged vessels, not detecting non-UK vessels in the UK Exclusive Economic Zone, likely leading to underestimates in fulmar-vessel encounters in these waters. Concurrent vessel and fulmar tracks were available from 2009 to 2018, and were linearly interpolated to the same resolution, either 3 or 10 min intervals depending on the resolution of the fulmar tracks from each colony. The coordinates of the nearest fishing vessel were extracted for each interpolated fulmar location in $\mathrm{R}$, for a subset of complete tracks from 2018 and before ( $\mathrm{n}=92$ ) for which sufficient VMS data were available. A frequentist implementation of the Pirotta et al. (2018) Bayesian approach, using similar constraints, was then used to fit a 7-state hidden Markov model (HMM) in 'momentuHMM' (https://cran. r-project.org/web/packages/momentuHMM/). This implementation was based on the fulmar example in the 'momentuHMM' vignette (McClintock \& Michelot 2018) with the addition of a rest state. Briefly, our method assumes the occurrence of 7 states of movement: rest, transit (on outward journey, at fishing vessel or on return journey) and area-restricted search (ARS) (on outward journey, at fishing vessel or on return journey) (Table S3). These can be identified based on the step length and turning angle between interpolated points, while also incorporating distance and bearing to the nearest vessel and bearing to the colony. ARS is thought to correspond to foraging activity (Kareiva \& Odell 1987, Weimerskirch et al. 2007, Bennison et al. 2018). Initial values of the model parameters were selected through $k$-means clustering of step lengths and turning angles into 3 clusters, intended to represent rest, ARS and transit states. The initial values of the parameters of the state-dependent distribution of distance to the nearest vessel $(d)$ were selected based on the histogram of observed distances and prior knowledge that fulmars may direct their movement toward vessels from distances of up to $35 \mathrm{~km}$ (Pirotta et al. 2018; Table S4). The outputs of the 7-state HMM were used to estimate the proportion of time spent in vessel-associated ARS on a track-by-track basis, which was compared to the time spent in ARS away from detected vessels. Vessel gear type was not available for all VMS data, but where available, was used to investigate the frequency of occurrence of association with different types of fishing vessels. Gear types were grouped into 6 categories: trawlers, seines, longlines, gillnets, dredgers and traps/pots.

\subsection{Identifying three primary states of fulmar behaviour}

Next, we aimed to identify putative foraging behaviour using the features of fulmar tracks. All fulmar tracks were linearly interpolated to $10 \mathrm{~min}$ relocations, as this and subsequent analysis requires regular and uniform track point intervals. Trips were split into sections where gaps of $>1 \mathrm{~h}$ were present in the raw GPS data to avoid interpolating over large time intervals. A separate 3-state HMM was fitted to these interpolated tracks to infer rest, ARS (putative foraging) and transit states (Figs. S1 \& S2) irrespective of fishing vessel associations. In other words, while the 7-state HMM was used to differentiate specific vessel-associated ARS from other forms of ARS, this model was used to differentiate ARS from nonARS more generally. Step lengths and turning angles between points were used to fit this HMM, with initial values of the parameters chosen using the same $k$-means procedure as for the 7 -state model (Table S5). The 'viterbi' function in 'MomentuHMM' was used to obtain the most likely state sequence for each track. These inferred states were used to represent putative foraging and non-foraging behaviour, and to investigate foraging habitat preferences. One caveat of this approach is that it does not account for differences in search-type behaviour (ARS) during vessel-attendance or natural foraging, although the scales of movement are assumed to be similar (Pirotta et al. 2018). 


\subsection{Fulmar foraging habitat preference modelling}

Fulmar foraging habitat preference was modelled using the outputs of the 3-state (rest, travel and ARS) HMM applied to the full tracking data. The response variable was presence or absence of ARS behaviour on each track point. To increase the accuracy in the absence data, only fixes classified as transit behaviour were retained to represent non-foraging, as rest can be difficult to discern from ARS without additional data, for example from time-depth recorders (Dean et al. 2013, Browning et al. 2018, Bennison et al. 2019). This response variable was modelled as a function of a set of fixed and dynamic covariates using binomial generalised additive mixed models (GAMMs) with a logit link function. Individual ID was included as a random effect. The 'mgcv' package was used for model fitting (https://cran.r-project.org/web/ packages/mgcv/). The 'bam' function was used, because, while the autocorrelation estimation is more flexible in the 'gamm' function, the associated computation times were not feasible for this dataset. Skewed covariates were transformed towards normal using an optimised Box-Cox transformation factor (Box \& Cox 1964; see Table S6), derived using the package 'EnvStats' (https://cran.r-project.org/web/ packages/EnvStats/). Covariates highly correlated with one or more other covariates were identified and removed stepwise using the 'concurvity' function in 'mgcv'. A high acceptable threshold of 0.8 was chosen for this process, as important partial effects may be expressed by related variables. This is especially true in biological settings with large sample sizes. The process by which 'mgcv' fits GAMMs also mitigates against the negative impacts of multicollinearity through backfitting of covariates (Wood 2008). The model was initially fit with a correlation parameter $(\rho)$ of 0 (i.e. assuming no autocorrelation among residuals) grouped according to individual trip. The autocorrelation function $(\mathrm{ACF})$ plot of the residuals of this model was then used to identify a suitable $\rho$, the value of the correlation between consecutive residuals. The shape of the ACF plot was also used to verify that a first-order autoregressive (AR(1)) structure provided a good representation of the autocorrelation present. Thin-plate regression splines with shrinkage were used for all predictor variables, which return the simplest effective spline, with complexity further restricted by setting the gamma parameter to 1.2, which increases the nullspace penalty when fitting the model (Wood 2003). This method avoids overfitting without having to arbitrarily constrain splines prior to model fitting. A whole-model approach using Akaike's information criterion (AIC) was used for model selection using the 'dredge' function in the 'MuMIn' package (https:// cran.r-project.org/web/packages/MuMIn/). Moran's Index (MI) was calculated on the spatial distribution of residuals to investigate spatial autocorrelation in the model using the 'ape' package (https://cran. r-project.org/web/packages/ape/). A low MI value of 0.063 suggests that spatial autocorrelation was minimal, so no corrective spatial smooth was included in the model.

Physical habitat variables that may influence the availability of fulmar prey were chosen following Cox et al. (2018). These variables were depth, a seabed terrain ruggedness index (TRI; Wilson et al. 2007), stratification (Hunter-Simpson parameter; Simpson \& Hunter 1974) and distance to the coast (km). These static environmental habitat predictors were handled as raster layers using the 'raster' package. Bathymetric data (TRI, depth) were sourced from a harmonised digital terrain model from the EMODnet database (https://portal.emodnet-bathymetry.eu). TRI identifies changes in seabed depth creating areas of complex currents, upwellings and internal waves, which are all known to enhance prey availability (Embling et al. 2012, Scott et al. 2013). Depth was included, as water column mixing is exaggerated in shallower waters, where tides interact more with the seabed (Cox et al. 2018). Stratification index was calculated as the Hunter-Simpson stratification parameter (Simpson \& Hunter 1974) formulated from depth and maximum tidal current speed. Current information was provided at $1.5 \mathrm{~km}$ resolution, sourced from the Copernicus Analysis tool using the Atlantic Marginal Model (AMM15) available from the Marine Environmental Monitoring Service (Tonani et al. 2019). Maximum tidal current speeds were calculated from a 14 d spring-neap cycle. Stratification identifies mixed $(<1.9)$, frontal (1.9) and stratified waters $(>1.9)$, with fronts assumed to enhance prey availability (Scales et al. 2014, Waggitt et al. 2018). Prey availability may also be increased by intense mixing of the water column in areas of low stratification (Benjamins et al. 2015, Waggitt et al. 2016). TRI and stratification data were resampled to a $1 \mathrm{~km}$ resolution using a bilinear interpolation.

The Global Fishing Watch (GFW) Automatic Identification System (AIS) database was used to calculate commercial fishing effort across the region of interest at a $0.01 \times 0.01^{\circ}$ spatial resolution. These AIS data differ from the VMS data used to run the 7 -state HMM in that they provide the spatial distribution of commercial fishing effort with greater coverage, 
while VMS returns the tracks of individual, identifiable fishing vessels. Fishing effort was calculated from hours fished only, so excluded vessels that were present but not thought to be engaged in fishing activity by the GFW process, which accurately differentiates fishing from non-fishing in $>90 \%$ of cases (Kroodsma et al. 2018). We acknowledge that vessels may release offal/discards when in transit rather than when actively fishing, but this process sought to identify the broad spatial distribution of fisheries activity. The 7-state HMM inferred fulmars foraging in association with all major gear types (see Section 3). Another model was run with fisheries data split according to gear type, with model selection performed using the same process as for the generalised fishing effort model. The gear-type model was compared to the base model using AIC to assess the utility of gear-specific fisheries data in explaining fulmar foraging distribution. Fishing effort was observed to be spatially consistent across summer months (Tables S7 \& S8, Figs. S3 \& S4), and fishing hours from 2012 to 2018 were averaged across all of May to August (the breeding season for fulmars) in each grid cell to provide a representation of broadscale fishing effort. The data were smoothed to $5 \times$ $5 \mathrm{~km}$ rolling averages and assigned to track points using the 'raster' package. Point-specific monthly SST $\left({ }^{\circ} \mathrm{C}\right)$ and chl a $\left(\mathrm{mg} \mathrm{m}^{-3}\right)$ values were sourced from NASA's Ocean Biology Processing Group service (https://oceancolor.gsfc.nasa.gov/13/), and appended to track points using Movebank's bilinear interpolation and inverse distance-weighted processes, respectively (Dodge et al. 2013).

The goodness of fit (GOF) of the final model was assessed by measuring the area under the receiver operating characteristic curve (AUC). A confusion matrix and associated accuracy were also included using the packages 'PresenceAbsence' (https://cran. r-project.org/web/packages/PresenceAbsence/) and 'caret' (https://cran.r-project.org/web/packages/caret/), because AUC has limitations as a measure of GOF (Lobo et al. 2008). The effect of each covariate was plotted using the 'mgcViz' package (https://cran.r-project .org/web/packages/mgcViz/). The contribution of each covariate to model GOF was also estimated by removing the variable and calculating the change in AUC. The suitability of foraging habitat was then predicted over the range of the tracking data in each area by applying the model to a raster stack of static covariates. Chl $a$ and SST summer averages from 2002 to 2020 were used in this prediction and were again sourced from NASA's OBPG (https://oceancolor.gsfc.nasa. gov/13/).

\section{RESULTS}

We obtained tracking information from 102 breeding fulmars between 2009 and 2019. A total of 184 partial or full foraging trips were recorded from tracked individuals. No distinct differences in distance travelled or proportion of time in ARS were observed between different geographical areas (Tables S1 \& S2). The distribution of tracks covered extensive areas of the southeast Celtic Sea, northwest North Sea and northeast Atlantic (Fig. 2)

\subsection{Fishing vessel association and behaviour}

Of the 102 tagged birds, 76 had complete foraging trips required for the 7-state HMM to infer direct vessel association. Of these 76 individuals, 41 were identified as engaging in vessel-associated ARS. Fig. 3 shows an example of a fulmar track inferred to have engaged in both natural and vessel-associated ARS over the course of $54 \mathrm{~h}$ in the Celtic Deep, a heavily fished area in the Celtic Sea. Within all trips analysed, a greater proportion of time was allocated to non-vessel-associated ARS (29.9\%) than to vesselassociated ARS (9.5\%) (Fig. 4). Within the trips in which vessel-associated ARS was detected, almost half of the time spent in ARS was spent in association with vessels $(46.2 \pm 30.1 \% \mathrm{SD})$. Most of the vesselassociated ARS occurred in the presence of trawlers $(83.2 \%)$, consistent with the prevalence of trawler fisheries in the study area and the quantity of discards and offal they produce (Marine Institute \& Bord

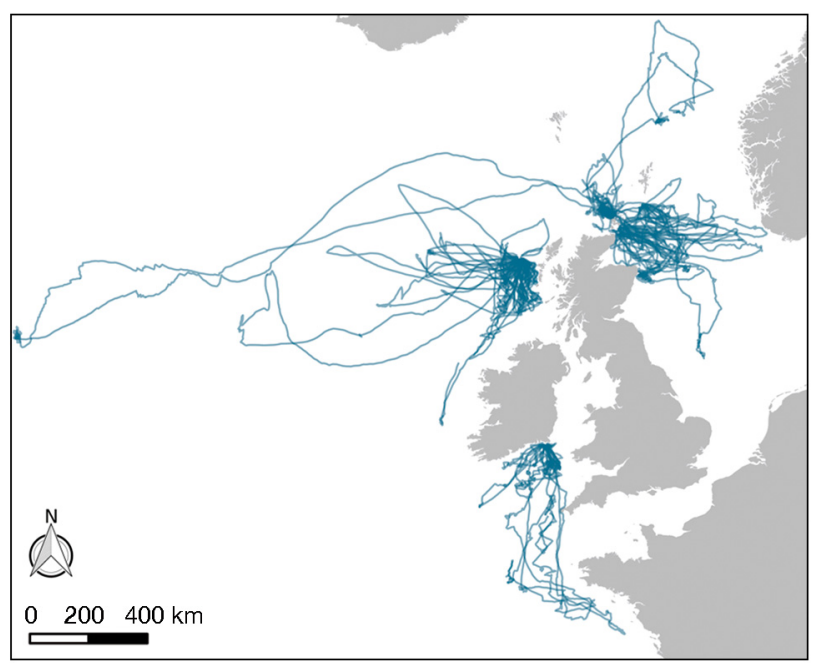

Fig. 2. GPS tracks from 102 adult fulmars in Scottish, Irish and Scilly Island colonies, 2009-2019 


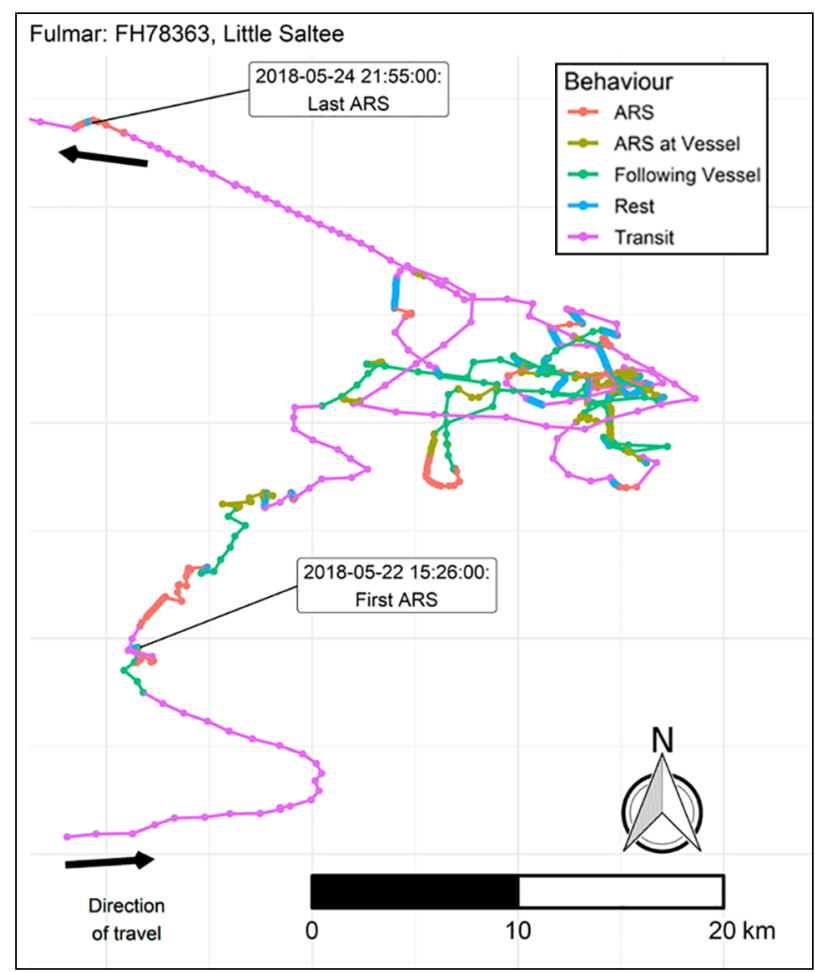

Fig. 3. Fulmar track annotated with behaviours inferred by the 7 -state hidden Markov model (HMM). This example has track points identified by the model as area-restricted search (ARS) in association with fishing vessels, as well as in the absence of detected vessels. It also has examples of vessel-following, rest and transit states

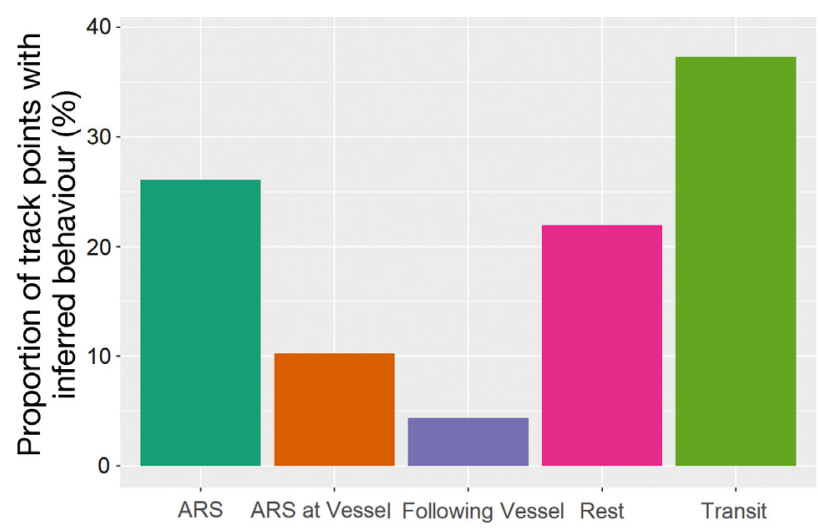

Fig. 4. Proportion of time fulmars spent in each behaviour according to the 7-state hidden Markov model (HMM). Transit and area-restricted search (ARS) states in the absence of a detected fishing vessel have been grouped to leave 5 behaviour classes

Iascaigh Mhara 2011). Fulmars showed vessel interactions with all gear types, although longliners $(<0.1 \%)$, trappers and potters $(0.9 \%)$ and gillnetters $(1.5 \%)$ only accounted for a small proportion of interactions (Fig. 5).

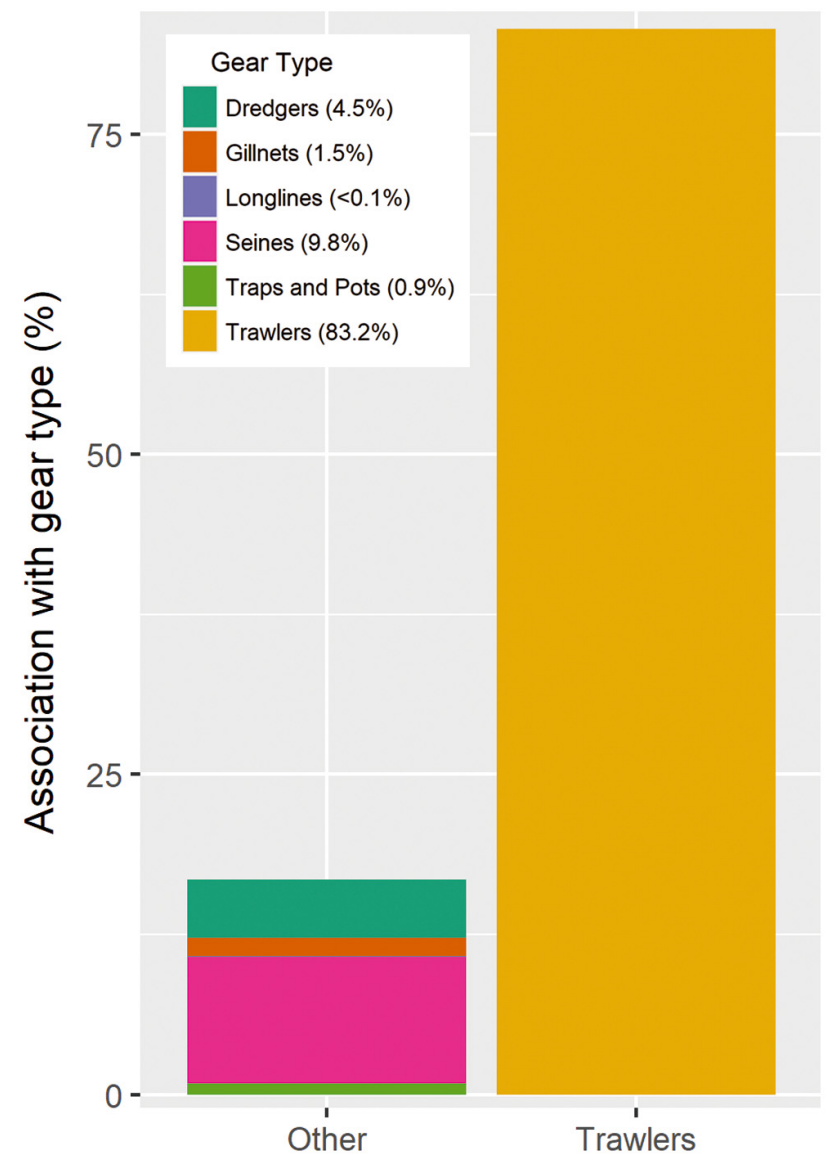

Fig. 5. Vessel gear types with which fulmars associated according to the 7-state hidden Markov model (HMM). Proportion of points (\%) spent in association with each vessel is shown in the legend

The outputs of the simplified HMM suggested that ARS and non-ARS states were roughly evenly distributed within trips, with $46 \%$ ARS (or putative foraging), $32 \%$ transit and $22 \%$ rest across the full tracking dataset.

\subsection{Fulmar foraging habitat modelling}

Commercial fishing effort was selected as a predictor of putative foraging distribution and behaviour, and environmental variables retained were stratification, seabed roughness, SST and chl a concentration (Table 2). Commercial fishing effort made a much greater contribution to model GOF than other variables retained (Table 2). The effect of each retained covariate is shown in Fig. 6. ARS was more likely in poorly stratified/well-mixed waters with a stratification index $<3$ and unlikely in highly stratified waters. The probability of engaging 
Table 2. Retained habitat-preference generalised additive mixed model (GAMM) covariates associated with arearestricted search (ARS) behaviour of fulmars tracked from Irish, Scottish and Scilly Island colonies. Estimated degrees of freedom (EDF) represents the complexity of the model term, while $\chi^{2}$ represents the effect the term has on the model output. A p-value of $<0.05$ is considered significant. Change in the area under the receiver operating characteristic curve (AUC) of the model on removal of each variable is also included to represent variable effect on model goodness of fit. This table is ordered by $\chi^{2}$. See Fig. 6 for the marginal effects plots for each covariate

\begin{tabular}{|lrrrc|}
\hline Variable & EDF & $\chi^{2}$ & $\mathrm{p}$ & $\begin{array}{c}\text { Change } \\
\text { in AUC }(\%)\end{array}$ \\
\hline Fishing effort & 1.5 & 199.4 & $<0.001$ & 1.7 \\
Sea surface temperature & 0.9 & 25.7 & $<0.001$ & 0.1 \\
Stratification & 0.9 & 23.3 & 0.001 & $<0.1$ \\
Chlorophyll a & 0.8 & 9.1 & 0.015 & 0.1 \\
Seabed roughness & 0.9 & 8.8 & 0.003 & 0.3 \\
\hline
\end{tabular}

in ARS increased with increasing commercial fishing effort, chl a concentration, SST and seabed roughness. Model AUC was $74.6 \%$ and the prediction accuracy was $69 \%$. These figures both suggest that the model has a moderate predictive power. A confusion matrix was constructed to compare predicted vs. actual values from the model outputs (Table 3).

When commercial fishing effort was split according to gear type, model fit improved according to AIC
Table 3. Confusion matrix to assess the goodness of fit of the fulmar foraging habitat preference model by comparing model predictions to hidden Markov model (HMM)-estimated behaviours. Agreement between the habitat preference model prediction and HMM is seen as validation of that prediction's accuracy, while disagreement is assumed to represent habitat preference model inaccuracy. The prediction accuracy of this model is $69 \%$. ARS: area-restricted search

\begin{tabular}{|lcc|}
\hline & $\begin{array}{c}\text { HMM-estimated } \\
\text { transit }\end{array}$ & $\begin{array}{c}\text { HMM-estimated } \\
\text { ARS }\end{array}$ \\
\hline Predicted transit & 5770 & 3751 \\
Predicted ARS & 2715 & 8641 \\
\hline
\end{tabular}

(11 198 with generalised fishing effort, 11174 with fishing effort split by gear types). Trawler and gillnet fishing effort were retained by the model, with other fishing gears dropped by the model selection process (Table S8). Non-trawler fishing effort covariates were heavily positively skewed due to the reduced prevalence of these fisheries within the range of the tracked fulmars, leading to high power transformation factors (Box \& Cox 1964) and limiting the utility of these covariates. Generalised fishing effort alone provided a better explanatory variable than retained gear-specific efforts (Table 2; Table S8), and because the tracked fulmars were shown to interact with all major fishing gear types, the model including generalised fishing effort was used for subsequent foraging habitat prediction.
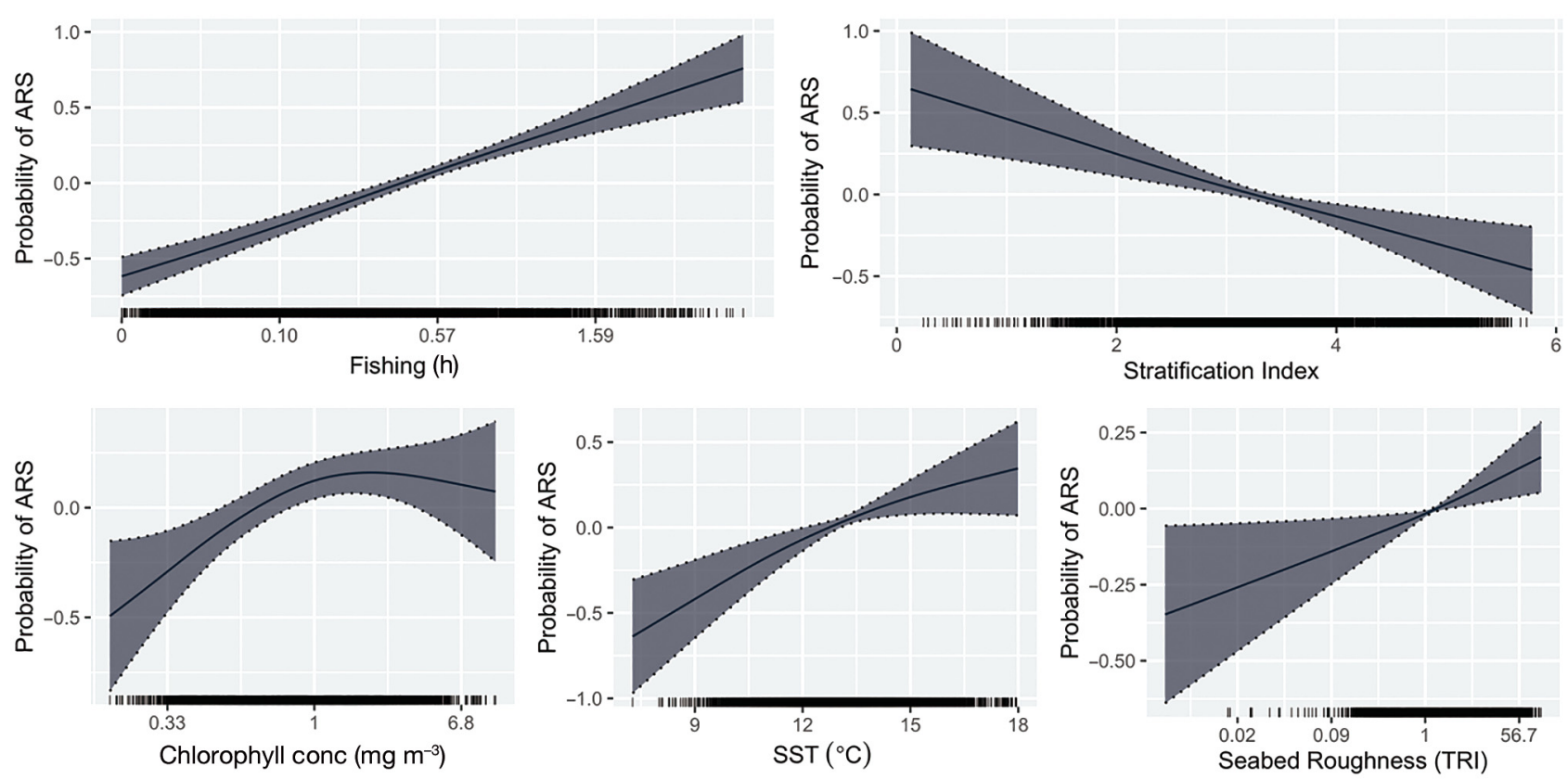

Fig. 6. Marginal effects of each model covariate on the probability of area-restricted search (ARS) behaviour prediction in fulmars. Dotted lines and shaded grey represent $95 \%$ confidence intervals. The rugplots at the base of the graphs represent the distribution of values of each covariate in the model dataset. SST: sea surface temperature; TRI: terrain ruggedness index 


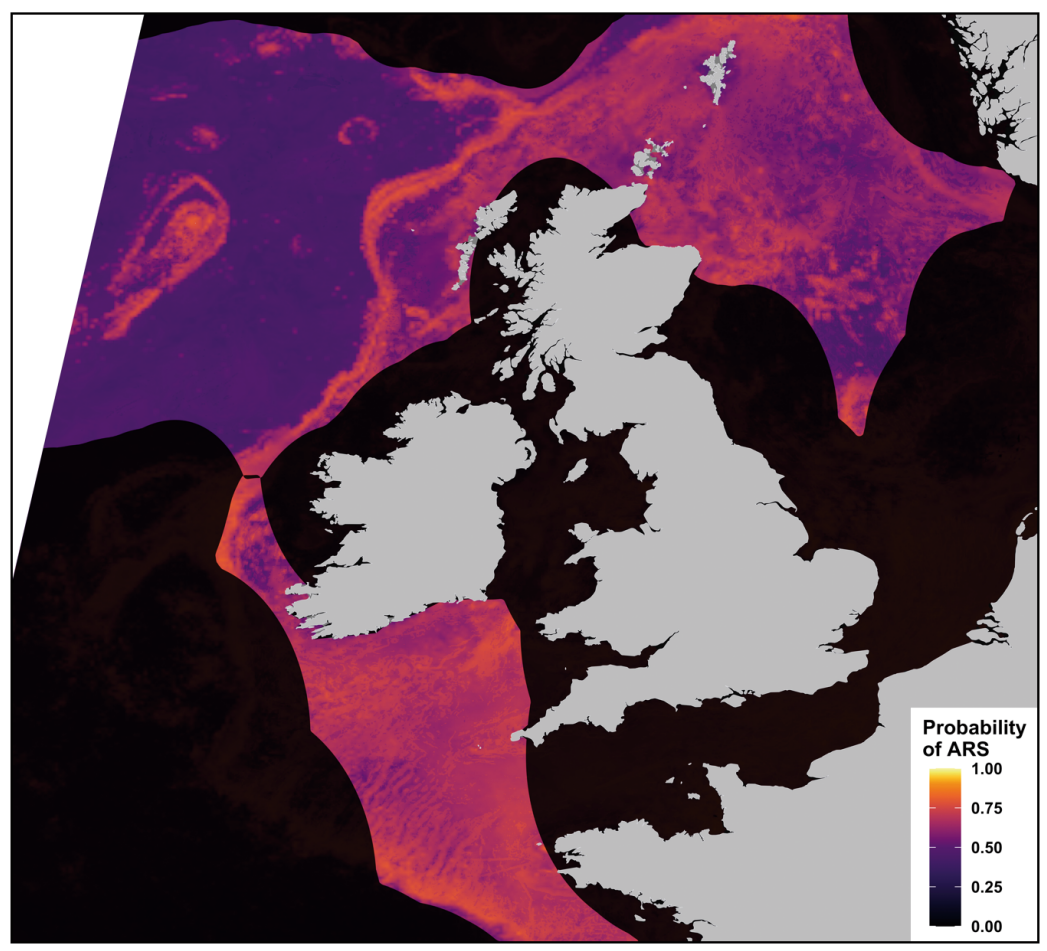

Fig. 7. Output of the fulmar foraging habitat-preference model extrapolated over the study areas. Care has been taken to avoid predicting across the area for which we do not have tracking data. Values correspond to probability of a fulmar performing area-restricted search (ARS) in an area if present, from 0 (improbable) to 1 (probable)

The spatial predictions from the model for each study area are shown in Fig. 7. Large oceanographic features, such as the continental shelf edge, the Rockall Bank and the Norwegian Trench are highlighted as important foraging habitat. Intensely fished areas, such as the Celtic Deep, much of the continental shelf edge and the central North Sea, are also areas of abundant foraging opportunities for breeding fulmars. Closer to shore, areas with a high degree of mixing are identified as important, such as the southeast corner of Ireland (around Little Saltee) and the Pentland Firth between the Scottish mainland and Orkney.

\section{DISCUSSION}

Our study highlights high foraging effort in areas of persistently high fishing effort as well as a prevalence of vessel interactions in breeding fulmars. Of the tracked fulmars, $54 \%$ associated with vessels on foraging trips, and for those birds known to forage at vessels, roughly half of their time spent in ARS was in the presence of vessels. This provides important context for the elevated bycatch levels for this species
(Dunn \& Steel 2001, Fangel et al. 2015), as well as the range expansion of the last centuries (Fisher 1952). Not only does this finding improve our understanding of the distribution of fulmars and their use of anthropogenic food subsidies, it also provides insight into how the foraging distribution of this species may be changing with shifting fisheries distribution, policies and practices. On a broader scale, our study also suggests that anthropogenic factors should be considered when discussing the distribution and behaviour of species, such as the fulmar, that alter their habits in response to human activities.

The high degree of putative foraging in association with fishing vessels points to the potential importance of fisheries byproducts (discarded fish, offal, bait) in the diet of this species (Ojowski et al. 2001). This is likely exaggerated in breeding individuals, whose foraging range is central-place constrained by needing to return to the nest for incubation, chick-rearing and provisioning duties (Edwards et al. 2016). Dupuis et al. (2021) showed that fulmars interact with vessels throughout the non-breeding season, but that interactions were more prevalent in parts of their range closer to breeding colonies. This suggests that vessel attendance may be more common when central-place foraging compared to less restricted periods of their annual cycle. Fisheries waste and depredation opportunities may increase food availability within their restricted breeding range (Bicknell et al. 2013) and widen diet to include species otherwise physically out of reach (Hudson \& Furness 1988, Thompson et al. 1995, Phillips et al. 1999) of this surface-feeding species. However, vessel interactions may also result in bycatch, and rates of vessel-associated foraging noted in this study are consistent with the high incidence of bycatch of fulmars relative to other seabird species (Dunn \& Steel 2001, Fangel et al. 2015). Over half of the tracked fulmars associated with vessels, and of all ARS detected in the analysis, $30 \%$ was associated with fishing vessels. This is also likely to be an underestimate given that VMS data do not include vessels under $12 \mathrm{~m}$ length or those fishing illegally, as well as UK VMS data not capturing non-UK vessels (see Section 2.2). There may also be 
a mismatch in the quantity of VMS data available across different time periods, as proportionally more vessels in the European fleet are fitted with VMS transponders over time (O'Shea \& Thompson 2006), with similar patterns apparent in AIS data (Fig. S4).

The degree to which fulmars associated with vessels across our tracking dataset is also reflected in persistent fishing effort being a significant predictor of fulmar foraging habitat. According to model outputs, anthropogenic fishing effort was a better predictor of fulmar habitat preference than oceanographic covariates typically used in species distribution models, including chl a concentration, SST, seabed roughness and stratification (e.g. Camphuysen \& Garthe 1997, Skov \& Durinck 2001, Kane et al. 2020). The recent decline of this species, as well as importance of intensely fished areas for foraging fulmars, highlights the need for targeted conservation that may involve adaptation of fishing gears or fishing practices to mitigate bycatch risk (Løkkeborg 2011, Domingo et al. 2017, Da Rocha et al. 2021). This study would also suggest that negative effects of other threats to fulmars such as oil pollution could be compounded if present in areas of intense fishing activity.

Despite fulmars being known consumers of fishery discards (Ojowski et al. 2001), the described effects of fishing vessels on fulmar foraging behaviour and distribution could arguably be due to both fulmars and fisheries targeting similar areas. While we cannot rule this out entirely, a recent study on the similarly sized, generalist, surface-feeding procellariform Cory's shearwater Calonectris borealis (Granadeiro et al. 1998) found very little overlap with fishing activity within its range (Pereira et al. 2021). Cory's shearwaters are not thought to habitually associate with fishing vessels, and low overlap would suggest their natural prey is obtained in areas that are not heavily fished. This supports the suggestion that fulmar foraging habitat being associated with fishing effort is due to fulmars concentrating ARS over areas of known intense fisheries, as Collet \& Weimerskirch (2020) demonstrated in black-browed albatrosses Thalassarche melanophris, which were shown to direct foraging effort towards areas where they had previously encountered fishing vessels. Blackbrowed albatrosses are also known to take fishery discards (Mariano-Jelicich et al. 2014).

Fulmars still directed considerable foraging effort towards natural prey, with more foraging occurring in the absence of detected vessels. This is reflected in the contribution of environmental covariates to the foraging habitat preference model. Although natural prey species of fulmars are trophically distinct from primary producers (Furness \& Todd 1984), chl a concentration was nevertheless identified as a significant predictor of fulmar foraging behaviour, consistent with studies in other procellariforms (Kane et al. 2020) as well as other marine predators (Russell et al. 1999, Cox et al. 2016). Areas of low stratification, or well-mixed waters, may be of benefit to fulmars through the accumulation and aggregation of zooplankton by complex flow structures (Benjamins et al. 2015). Seabed roughness may also contribute to the complexity of flow structures and increase the availability of prey (Cox et al. 2018) as well as being unsuitable for many demersal fisheries due to risk of loss or damage to fishing gears through snagging on complex seabed terrain.

Fisheries are dynamic, and influenced by governance, market demand, policy and infrastructure (ports, harbours, etc.) as well as fish stock levels and distribution shifts due to climate change (Perry et al. 2005). The foraging distribution of fulmars and other discard-reliant species is therefore linked to the same range of socioeconomic and environmental factors. The European Union initiated a discard ban, or landing obligation, in 2015, calling on fishing vessels to cease the disposal of bycaught non-target species at sea (Borges 2021). Fulmars are known to take a range of fisheries byproducts, including offal and longline bait (Phillips et al. 1999), though our study has shown that fulmars have a clear affinity towards trawler vessels, the major proprietor of discards in the study region (Marine Institute \& Bord Iascaigh Mhara 2011). With discard rates presumably decreasing, it would be expected that fulmars may shift their fishing effort either towards natural prey, or towards other fishing gears with available byproducts. This may lead to increased associations with longline, gillnet and purse seine vessels, where fulmars can depredate bait or assimilated prey, although this in turn may cause increased rates of bycatch from fulmars getting caught in these gears (Dunn \& Steel 2001).

Including fishing effort as a covariate in foraging habitat preference analysis may be useful for a range of species that take discards, target similar prey species to fisheries, or even actively avoid vessels. More generally, including anthropogenic factors in habitat models can improve our understanding of species distribution and behaviour across a range of taxa. For example, Russell et al. (2014) showed that windfarms can influence the foraging behaviour of seals by creating artificial reefs and excluding fisheries, both thought to lead to increased abundance of prey. Sim- 
ilarly, Lieber et al. (2019) showed how a persistent artificial wake created by a wave power harvester created a foraging hotspot for surface-feeding seabirds through persistent mixing of the water column. Human industry is shaping the habits and habitats of species, and this study highlights the value of considering such anthropogenic factors when investigating species' ecology.

Acknowledgements. J.H.D. was funded by the Irish Research Council Enterprise Partnership Scheme, supported by the Petroleum Infrastructure Program. Field work on Little Saltee in 2018 and 2019 and S.d.G. were funded by the BlueFish project, funded by the European Regional Development fund through the Ireland Wales Co-operation Programme 2014-2020. Fieldwork on Eynhallow and St. Kilda was supported by Orkney Islands Council, the University of Aberdeen, the National Trust for Scotland and Talisman Energy (UK) Ltd. E.W.J.E. was funded by a Marine Alliance for Science and Technology for Scotland and University of Aberdeen studentship. Fieldwork elsewhere was funded by the EU Atlantic area INTERREG program via the Future of the Atlantic Marine Environment (FAME) project and by the RSPB, JNCC, Fair Isle Bird Observatory Trust and Marine Scotland, through the Seabird Tracking And Research (STAR) project. We are grateful for field assistance from Ash Bennison, Cian Luck, Yvan Satge, Juliet Lamb, Chris Bell, Mara Nydegger, Robert Hughes, Elizabeth Mackley, Richard Bufton, Jenni Border, Derren Fox, Tegan Newman, Daisy Burnell, Antoine Grissott and Chris Taylor. Marine Scotland Science and the Marine Institute provided access to anonymized VMS data. G.E.A. was funded by the MarPAMM project supported by the EU INTERREG VA Programme, managed by the Special EU Programmes Body (SEUPB). The views and opinions expressed in this manuscript do not necessarily reflect those of the European Commission or the SEUPB. Go raibh míle maith agaibh, Pat and Liezel of Little Saltee for their outstanding support and hospitality.

\section{LITERATURE CITED}

Acampora H, Newton S, O'Connor I (2017) Opportunistic sampling to quantify plastics in the diet of unfledged black legged kittiwakes (Rissa tridactyla), northern fulmars (Fulmarus glacialis) and great cormorants (Phalacrocorax carbo). Mar Pollut Bull 119:171-174

Amorim P, Figueiredo M, Machete M, Morato T, Martins A, Serrão Santos R (2009) Spatial variability of seabird distribution associated with environmental factors: a case study of marine important bird areas in the Azores. ICES J Mar Sci 66:29-40

Benjamins S, Dale A, Hastie G, Waggitt J, Lea MA, Scott B, Wilson B (2015) Confusion reigns? A review of marine megafauna interactions with tidal-stream environments. Oceanogr Mar Biol Annu Rev 53:1-54

Bennison A, Bearhop S, Bodey TW, Votier SC and others (2018) Search and foraging behaviors from movement data: a comparison of methods. Ecol Evol 8:13-24

Bennison A, Quinn JL, Debney A, Jessopp M (2019) Tidal drift removes the need for area restricted search in foraging Atlantic puffins. Biol Lett 15:20190208
Bicknell AWJ, Oro D, Camphuysen KCJ, Votier SC (2013) Potential consequences of discard reform for seabird communities. J Appl Ecol 50:649-658

Bodey TW, Jessopp MJ, Votier SC, Gerritsen HD and others (2014) Seabird movement reveals the ecological footprint of fishing vessels. Curr Biol 24:R514-R515

* Borges L (2021) The unintended impact of the European discard ban. ICES J Mar Sci 78:134-141

Box GEP, Cox DR (1964) An analysis of transformations. J R Stat Soc Ser B Stat Methodol 26:211-243

* Boyd C, Castillo R, Hunt GL Jr, Punt AE, VanBlaricom GR, Weimerskirch H, Bertrand S (2015) Predictive modelling of habitat selection by marine predators with respect to the abundance and depth distribution of pelagic prey. J Anim Ecol 84:1575-1588

Browning E, Bolton M, Owen E, Shoji A, Guilford T, Freeman R (2018) Predicting animal behaviour using deep learning: GPS data alone accurately predict diving in seabirds. Methods Ecol Evol 9:681-692

Burg TM, Lomax J, Almond R, Brooke MDL, Amos W (2003) Unravelling dispersal patterns in an expanding population of a highly mobile seabird, the northern fulmar (Fulmarus glacialis). Proc R Soc B 270:979-984

Caldwell A, Seavey J, Craig E (2020) Foraging strategy impacts plastic ingestion risk in seabirds. Limnol Oceanogr Lett 5:163-168

Camphuysen K, Garthe S (1997) An evaluation of the distribution and scavenging habits of northern fulmars (Fulmarus glacialis) in the North Sea. ICES J Mar Sci 54: 654-683

Clay TA, Small C, Tuck GN, Pardo D and others (2019) A comprehensive large-scale assessment of fisheries bycatch risk to threatened seabird populations. J Appl Ecol 56:1882-1893

Cleasby IR, Morrissey BJ, Bolton M, Owen E, Wilson L, Wischnewski S, Nakagawa S (2021) What is our power to detect device effects in animal tracking studies? Methods Ecol Evol 12:1174-1185

Collet J, Weimerskirch H (2020) Albatrosses can memorize locations of predictable fishing boats but favour natural foraging. Proc R Soc B 287:20200958

* Cordes LS, Hedworth HE, Cabot D, Cassidy M, Thompson PM (2015) Parallel declines in survival of adult northern fulmars Fulmarus glacialis at colonies in Scotland and Ireland. Ibis 157:631-636

Cosgrove R, Cronin M, Reid D, Gosch M, Sheridan M, Chopin N, Jessopp M (2013) Seal depredation and bycatch in set net fisheries in Irish waters. Fisheries Resource Series 10. Irish Sea Fisheries Board (Bord Iascaigh Mhara), Dublin

Cox SL, Miller PI, Embling CB, Scales KL and others (2016) Seabird diving behaviour reveals the functional significance of shelf-sea fronts as foraging hotspots. R Soc Open Sci 3:160317

Cox SL, Embling CB, Hosegood PJ, Votier SC, Ingram SN (2018) Oceanographic drivers of marine mammal and seabird habitat-use across shelf-seas: a guide to key features and recommendations for future research and conservation management. Estuar Coast Shelf Sci 212: 294-310

* Critchley EJ, Grecian WJ, Kane A, Jessopp MJ, Quinn JL (2018) Marine protected areas show low overlap with projected distributions of seabird populations in Britain and Ireland. Biol Conserv 224:309-317

* Critchley EJ, Grecian WJ, Bennison A, Kane A and others 
(2020) Assessing the effectiveness of foraging radius models for seabird distributions using biotelemetry and survey data. Ecography 43:184-196

Cronin M, Gerritsen H, Reid D, Jessopp M (2016) Spatial overlap of grey seals and fisheries in Irish waters, some new insights using telemetry technology and VMS. PLOS ONE 11:e0160564

Da Rocha N, Oppel S, Prince S, Matjila S and others (2021) Reduction in seabird mortality in Namibian fisheries following the introduction of bycatch regulation. Biol Conserv 253:108915

Dean B, Freeman R, Kirk H, Leonard K, Phillips RA, Perrins CM, Guilford T (2013) Behavioural mapping of a pelagic seabird: combining multiple sensors and a hidden Markov model reveals the distribution of at-sea behaviour. J R Soc Interface 10:20120570

* Dietrich KS, Parrish JK, Melvin EF (2009) Understanding and addressing seabird bycatch in Alaska demersal longline fisheries. Biol Conserv 142:2642-2656

Dodge S, Bohrer G, Weinzierl R, Davidson SC and others (2013) The environmental-data automated track annotation (Env-DATA) system: linking animal tracks with environmental data. Mov Ecol 1:3

* Domalik AD, Hipfner JM, Studholme KR, Crossin GT, Green DJ (2018) At-sea distribution and fine-scale habitat use patterns of zooplanktivorous Cassin's auklets during the chick-rearing period. Mar Biol 165:177

* Domingo A, Jiménez S, Abreu M, Forselledo R, Yates O (2017) Effectiveness of tori line use to reduce seabird bycatch in pelagic longline fishing. PLOS ONE 12: $\mathrm{e} 0184465$

Dunn E, Steel C (2001) The impact of longline fishing on seabirds in the north-east Atlantic: recommendations for reducing mortality. NOF Rapportserie Rep No 5. The Royal Society for the Protection of Birds (RSPB), Sandy. https:// www.rspb.org.uk/globalassets/downloads/documents/ positions/marine/the-impact-of-longline-fishing-onseabirds-in-the-north-east-atlantic--recommendationsfor-reducing-mortality.pdf

Dupuis B, Amélineau F, Tarroux A, Bjørnstad O and others (2021) Light-level geolocators reveal spatial variations in interactions between northern fulmars and fisheries. Mar Ecol Prog Ser 676:159-172

Edwards EWJ, Quinn LR, Thompson PM (2016) State-space modelling of geolocation data reveals sex differences in the use of management areas by breeding northern fulmars. J Appl Ecol 53:1880-1889

Elith J, Leathwick JR (2009) Species distribution models: ecological explanation and prediction across space and time. Annu Rev Ecol Evol Syst 40:677-697

Embling CB, Illian J, Armstrong E, van der Kooij J, Sharples J, Camphuysen KCJ, Scott BE (2012) Investigating finescale spatio-temporal predator-prey patterns in dynamic marine ecosystems: a functional data analysis approach. J Appl Ecol 49:481-492

Fangel K, Aas Ø, Vølstad JH, Bærum KM and others (2015) Assessing incidental bycatch of seabirds in Norwegian coastal commercial fisheries: empirical and methodological lessons. Glob Ecol Conserv 4:127-136

Fauchald P (2009) Spatial interaction between seabirds and prey: review and synthesis. Mar Ecol Prog Ser 391: 139-151

Fisher J (1952) A history of the fulmar (Fulmarus) and its population problems. Ibis 94:334-354

Fox CH, O'Hara PD, Bertazzon S, Morgan K, Underwood
FE, Paquet PC (2016) A preliminary spatial assessment of risk: marine birds and chronic oil pollution on Canada's Pacific coast. Sci Total Environ 573:799-809

F Fryxell JM, Wilmshurst JF, Sinclair ARE (2004) Predictive models of movement by Serengeti grazers. Ecology 85: 2429-2435

Furness RW, Todd CM (1984) Diets and feeding of fulmars Fulmarus glacialis during the breeding season: a comparison between St Kilda and Shetland colonies. Ibis 126:379-387

Giménez J, Arneill G, Bennison A, Priotta E and others (2021) Sexual mismatch between vessel-associated foraging and discard consumption in a marine top predator. Front Mar Sci 8:636468

Gordon S (1936) The fulmar petrel. Nature 137:173-176

* Granadeiro JP, Monteiro LR, Furness RW (1998) Diet and feeding ecology of Cory's shearwater Calonectris diomedea in the Azores, north-east Atlantic. Mar Ecol Prog Ser 166:267-276

Grémillet D, Pichegru L, Kuntz G, Woakes AG, Wilkinson S, Crawford RJM, Ryan PG (2008) A junk-food hypothesis for gannets feeding on fishery waste. Proc R Soc B 275: 1149-1156

Hedd A, Regular PM, Wilhelm SI, Rail JF and others (2016) Characterization of seabird bycatch in eastern Canadian waters, 1998-2011, assessed from onboard fisheries observer data. Aquat Conserv 26:530-548

Hudson AV, Furness RW (1988) Utilization of discarded fish by scavenging seabirds behind whitefish trawlers in Shetland. J Zool (Lond) 215:151-166

JNCC (2020) Seabird population trends and causes of change: 1986-2018 Report. Joint Nature Conservation Committee, Peterborough. https://jncc.gov.uk/our-work/ smp-report-1986-2018

Kane A, Pirotta E, Wischnewski S, Critchley EJ, Bennison A, Jessopp M, Quinn JL (2020) Spatio-temporal patterns of foraging behaviour in a wide-ranging seabird reveal the role of primary productivity in locating prey. Mar Ecol Prog Ser 646:175-188

Kareiva P, Odell G (1987) Swarms of predators exhibit 'preytaxis' if individual predators use area-restricted search. Am Nat 130:233-270

Kroodsma DA, Mayorga J, Hochberg T, Miller NA and others (2018) Tracking the global footprint of fisheries. Science 359:904-908

* Lascelles BG, Langham GM, Ronconi RA, Reid JB (2012) From hotspots to site protection: identifying marine protected areas for seabirds around the globe. Biol Conserv 156:5-14

*Lieber L, Nimmo-Smith WAM, Waggitt JJ, Kregting L (2019) Localised anthropogenic wake generates a predictable foraging hotspot for top predators. Commun Biol 2:123

*Lobo JM, Jiménez-Valverde A, Real R (2008) AUC: a misleading measure of the performance of predictive distribution models. Glob Ecol Biogeogr 17:145-151

Løkkeborg S (2011) Best practices to mitigate seabird bycatch in longline, trawl and gillnet fisheries - efficiency and practical applicability. Mar Ecol Prog Ser 435: 285-303

Kariano-Jelicich R, Copello S, Seco Pon JP, Favero M (2014) Contribution of fishery discards to the diet of the blackbrowed albatross (Thalassarche melanophris) during the non-breeding season: an assessment through stable isotope analysis. Mar Biol 161:119-129

Marine Institute, Bord Iascaigh Mhara (2011) Atlas of dem- 
ersal discarding. Scientific observations and potential solutions. Marine Institute and Bord Iascaigh Mhara

McClintock BT, Michelot T (2018) momentuHMM: R package for generalized hidden Markov models of animal movement. Methods Ecol Evol 9:1518-1530

McGowan J, Hines E, Elliott M, Howar J, Dransfield A, Nur N, Jahncke J (2013) Using seabird habitat modeling to inform marine spatial planning in central California's national marine sanctuaries. PLOS ONE 8:e71406

Newsome TM, Van Eeden LM (2017) The effects of food waste on wildlife and humans. Sustainability 9:1269

Newsome TM, Dellinger JA, Pavey CR, Ripple WJ, Shores CR, Wirsing AJ, Dickman CR (2015) The ecological effects of providing resource subsidies to predators. Glob Ecol Biogeogr 24:1-11

Nur N, Jahncke J, Herzog MP, Howar J and others (2011) Where the wild things are: predicting hotspots of seabird aggregations in the California Current System. Ecol Appl 21:2241-2257

O'Shea B, Thompson S (2006) The innovative application of vessel monitoring systems for the effective fisheries monitoring control and surveillance. ICES CM 2006/N:11. https://www.ices.dk/sites/pub/CM\%20Doccuments/2006/ N/N1106.pdf

Ojowski U, Eidtmann C, Furness R, Garthe S (2001) Diet and nest attendance of incubating and chick-rearing northern fulmars (Fulmarus glacialis) in Shetland. Mar Biol 139:1193-1200

Paleczny M, Hammill E, Karpouzi V, Pauly D (2015) Population trend of the world's monitored seabirds, 1950-2010. PLOS ONE 10:e0129342

* Pereira JM, Ramos JA, Marques AM, Ceia FR, Krüger L, Votier SC, Paiva VH (2021) Low spatial overlap between foraging shearwaters during the breeding season and industrial fisheries off the west coast of Portugal. Mar Ecol Prog Ser 657:209-221

* Perry AL, Low PJ, Ellis JR, Reynolds JD (2005) Climate change and distribution shifts in marine fishes. Science 308:1912-1915

*Phillips RA, Petersen MK, Lilliendahl K, Solmundsson J, Hamer KC, Camphuysen CJ, Zonfrillo B (1999) Diet of the northern fulmar Fulmarus glacialis: reliance on commercial fisheries? Mar Biol 135:159-170

Pirotta E, Edwards EWJ, New L, Thompson PM (2018) Central place foragers and moving stimuli: a hidden-state model to discriminate the processes affecting movement. J Anim Ecol 87:1116-1125

R Core Team (2020) R: a language and environment for statistical computing. R Foundation for Statistical Computing, Vienna

Russell DJF, Brasseur SMJM, Thompson D, Hastie GD and others (2014) Marine mammals trace anthropogenic structures at sea. Curr Biol 24:R638-R639

Russell RW, Harrison NM, Hunt GL Jr (1999) Foraging at a front: hydrography, zooplankton, and avian planktivory in the northern Bering Sea. Mar Ecol Prog Ser 182:77-93

Sauvajot R, Buechner M, Kamradt D, Schonewald C (1998) Patterns of human disturbance and response by small mammals and birds in chaparral near urban development. Urban Ecosyst 2:279-297

Scales KL, Miller PI, Hawkes LA, Ingram SN, Sims DW, Votier SC (2014) On the front line: frontal zones as priority at-sea conservation areas for mobile marine vertebrates. J Appl Ecol 51:1575-1583

Scales KL, Miller PI, Ingram SN, Hazen EL, Bograd SJ,
Phillips RA (2016) Identifying predictable foraging habitats for a wide-ranging marine predator using ensemble ecological niche models. Divers Distrib 22:212-224

* Scott BE, Webb A, Palmer MR, Embling CB, Sharples J (2013) Fine scale bio-physical oceanographic characteristics predict the foraging occurrence of contrasting seabird species; gannet (Morus bassanus) and storm petrel (Hydrobates pelagicus). Prog Oceanogr 117:118-129

* Serratosa J, Hyrenbach KD, Miranda-Urbina D, PortflittToro M, Luna N, Luna-Jorquera G (2020) Environmental drivers of seabird at-sea distribution in the eastern South Pacific Ocean: assemblage composition across a longitudinal productivity gradient. Front Mar Sci 6:838

* Sherley RB, Ladd-Jones H, Garthe S, Stevenson O, Votier SC (2020) Scavenger communities and fisheries waste: North Sea discards support 3 million seabirds, 2 million fewer than in 1990. Fish Fish 21:132-145

Simpson JH, Hunter JR (1974) Fronts in the Irish Sea. Nature 250:404-406

K Skov H, Durinck J (2001) Seabird attraction to fishing vessels is a local process. Mar Ecol Prog Ser 214:289-298

* Smit IPJ (2011) Resources driving landscape-scale distribution patterns of grazers in an African savanna. Ecography 34:67-74

Stevick PT, Incze LS, Kraus SD, Rosen S, Wolff N, Baukus A (2008) Trophic relationships and oceanography on and around a small offshore bank. Mar Ecol Prog Ser 363: $15-28$

Thompson DR, Furness RW, Lewis SA (1995) Diets and longterm changes in $\delta^{15} \mathrm{~N}$ and $\delta^{13} \mathrm{C}$ values in northern fulmars Fulmarus glacialis from two northeast Atlantic colonies. Mar Ecol Prog Ser 125:3-11

Thompson PM (2006) Identifying drivers of change; did fisheries play a role in the spread of North Atlantic fulmars? In: Boyd IL, Wanless S, Camphuysen CJ (eds) Top predators in marine ecosystems: their role in monitoring and management. Cambridge University Press, Cambridge, p 143-156

Tonani M, Sykes P, King RR, McConnell N and others (2019) The impact of a new high-resolution ocean model on the Met Office North-West European Shelf forecasting system. Ocean Sci 15:1133-1158

*Torres LG, Sagar PM, Thompson DR, Phillips RA (2013) Scaling down the analysis of seabird-fishery interactions. Mar Ecol Prog Ser 473:275-289

* Torres LG, Sutton PJH, Thompson DR, Delord K and others (2015) Poor transferability of species distribution models for a pelagic predator, the grey petrel, indicates contrasting habitat preferences across ocean basins. PLOS ONE 10:e0120014

Tremblay Y, Bertrand S, Henry RW, Kappes MA, Costa DP, Shaffer SA (2009) Analytical approaches to investigating seabird-environment interactions: a review. Mar Ecol Prog Ser 391:153-163

* Tuck GN, Phillips RA, Small C, Thomson RB and others (2011) An assessment of seabird-fishery interactions in the Atlantic Ocean. ICES J Mar Sci 68:1628-1637

*Vandenabeele SP, Grundy E, Friswell MI, Grogan A, Votier SC, Wilson RP (2014) Excess baggage for birds: inappropriate placement of tags on gannets changes flight patterns. PLOS ONE 9:e92657

Vynne C, Keim JL, Machado RB, Marinho-Filho J, Silveira L, Groom MJ, Wasser SK (2011) Resource selection and its implications for wide-ranging mammals of the Brazilian Cerrado. PLOS ONE 6:e28939 
Waggitt JJ, Cazenave PW, Torres R, Williamson BJ, Scott BE (2016) Quantifying pursuit-diving seabirds' associations with fine-scale physical features in tidal stream environments. J Appl Ecol 53:1653-1666

Waggitt JJ, Cazenave PW, Howarth LM, Evans PGH, van der Kooij J, Hiddink JG (2018) Combined measurements of prey availability explain habitat selection in foraging seabirds. Biol Lett 14:20180348

Waggitt JJ, Evans PGH, Andrade J, Banks AN and others (2020) Distribution maps of cetacean and seabird populations in the North-East Atlantic. J Appl Ecol 57: 253-269

Weimerskirch H, Pinaud D, Pawlowski F, Bost CA (2007) Does prey capture induce area-restricted search? A fine-

Editorial responsibility: Kyle Elliott,

Sainte-Anne-de-Bellevue, Québec, Canada

Reviewed by: J. M Pereira and 2 anonymous referees scale study using GPS in a marine predator, the wandering albatross. Am Nat 170:734-743

* Whitehead H, O'Brien K, Worm B (2010) Diversity of deepwater cetaceans and primary productivity. Mar Ecol Prog Ser 408:1-5

*Wilson MFJ, O'Connell B, Brown C, Guinan JC, Grehan AJ (2007) Multiscale terrain analysis of multibeam bathymetry data for habitat mapping on the continental slope. Mar Geod 30:3-35

*Wood SN (2003) Thin plate regression splines. J R Stat Soc Ser B Stat Methodol 65:95-114

* Wood SN (2008) Fast stable direct fitting and smoothness selection for generalized additive models. J R Stat Soc Ser B Stat Methodol 70:495-518

Submitted: April 19, 2021

Accepted: September 1, 2021

Proofs received from author(s): November 22, 2021 